\title{
Self-assembled Zn-OPV Composite for Ammonia Sensing
}

\author{
Aaryashree $^{1}$, Biswajit Mandal', Ritesh Bhardwaj', Sayan Maiti ${ }^{2}$, Apurba K Das ${ }^{2}$, Shaibal Mukherjee ${ }^{1, *}$ \\ ${ }^{1}$ Hybrid Nanodevice Research Group (HNRG), Electrical Engineering, Indian Institute of Technology \\ Indore, Madhya Pradesh 453552, India \\ 2 Supramolecular Chemical Nanoscience Group (SCNG), Department of Chemistry, Indian Institute of \\ Technology Indore, Madhya Pradesh 453552, India. \\ *Email: shaibal@iiti.ac.in
}

\begin{abstract}
:
We have made an effort to demonstrate a simple and facile methodology i.e. electrodeposition for synthesizing oligo( $p$-phenylenevinylene(OPV) and Zn-OPV nanocomposites films. On combining the benefits of the two materials, it is seen that this structure exhibited more sensitive performance for ammonia sensing. The findings of this study showed that fabricating highly sensitive gas sensors with organic-inorganic semiconductors helped to reduce the operating temperature and, also paved way towards a more selective gas sensor.
\end{abstract}

Key words: $\mathrm{ZnO}$, functionalized-organic, hybrid, ammonia, sensing-application.

\section{Introduction}

In the past few decades, gas sensors based on metal oxide semiconductors have drawn much attention for numerous applications such as environmental monitoring, industrial process control, and for the detection of toxic substrates gases. [1,2] Further, the self-assembly of $\pi$ conjugated arrangements have paved way towards many interconnected advances in various fields. [3,4] In this perspective, we accomplished our goal of synthesising selfassembled hybrid nanostructures having both electronically active organic (i.e. oligo $(p$ phenylenevinylene) (OPV)) and inorganic (zinc oxide $(\mathrm{ZnO})$ ) components. One amongst the various noteworthy properties of $\mathrm{ZnO}$, is its rich and precisely accessible nanostructures.[5] Also, the supramolecular architectures of functionalized OPVs, which are driven by hydrogen bonding as well as $\pi-\pi$ stacking interactions, are highly regarded.[6]

These sensors with nanocomposites have improved the limitations of metal oxide semiconductors based sensors such as high working temperature, low selectivity, etc., and also minimised the thermal instability of organic gas sensors. Zn-OPV based gas sensor has shown high selectivity for ammonia $\left(\mathrm{NH}_{3}\right)$ and operated at a quite lower temperature.

\section{Experimental details}

The hybrid nanostructures were grown by electrodeposition on working electrodes (ITO coated glass) from zinc nitrate hexahydrate $\left(\mathrm{Zn}(\mathrm{NO})_{3} .6 \mathrm{H}_{2} \mathrm{O}\right)$ and surfactant in a solution of 1:1 (v/v) $\mathrm{H}_{2} \mathrm{O}$ /dimethylsulphoxide (DMSO). Prior to electrodeposition, the working electrodes were cleaned with DI water and purged with high-purity $(99.999 \%$ pure) nitrogen gas. Platinum (Pt) and silver/silver chloride $(\mathrm{Ag} / \mathrm{AgCl})$ were used as counter and reference electrodes, respectively.

The crystal structure and the phase composition were identified by RigakuSmartLab automated multi-purpose X-ray diffractometer with $\mathrm{Cu}-\mathrm{Ka} \mathrm{X}$-radiation $(\lambda=1.54 \AA)$. The morphology of the crystals was observed by field-emission scanning electron microscope (FE-SEM) by Sigma Supra ${ }^{\mathrm{TM}} 55$ of Carl Zeiss. The Autosorb iQ2 was used to determine specific surface area using the BrunauerEmmett-Teller (BET) method based on the $\mathrm{N}_{2}$ adsorption-desorption tests. Gas sensing properties of the samples were measured in a dynamic flow-through system.

\section{Results and discussions}

The FESEM images of $\mathrm{ZnO}, \mathrm{Zn}-\mathrm{OPV}$ nanocomposite samples are shown in Fig. 1(a) and 1 (b) respectively. In Fig. 1(a), deposition of randomly oriented $\mathrm{ZnO}$ cone-like structure can be noticed. Fig. 1(b) shows the FESEM of $\mathrm{Zn}$ OPV nano-composite deposited film. Fig 1 (c) shows the operating temperature optimization of the samples. From Fig 1 (c) it is clear that the Zn-OPV hybrid has a lower operating 
temperature than $\mathrm{ZnO}$. The optimised operating temperature is around $120{ }^{\circ} \mathrm{C}$. Fig 2(a) shows the response of all the samples towards ammonia $\left(\mathrm{NH}_{3}\right)$ at $120{ }^{\circ} \mathrm{C}$. It is clear from the responses that the $\mathrm{Zn}-\mathrm{OPV}$ samples are more sensitive towards ammonia gas. Calculating the response as $R_{g} / R_{a}$, it is found that the response of $\mathrm{Zn}-\mathrm{OPV}$ is approximately 8.5 at $10 \mathrm{ppm}$ of the analyte gas. However, this value is quite low in case of $\mathrm{ZnO}$ and OPV individually. Fig. 2 (b) shows transient response of $\mathrm{ZnO}$, OPV and Zn-OPV.
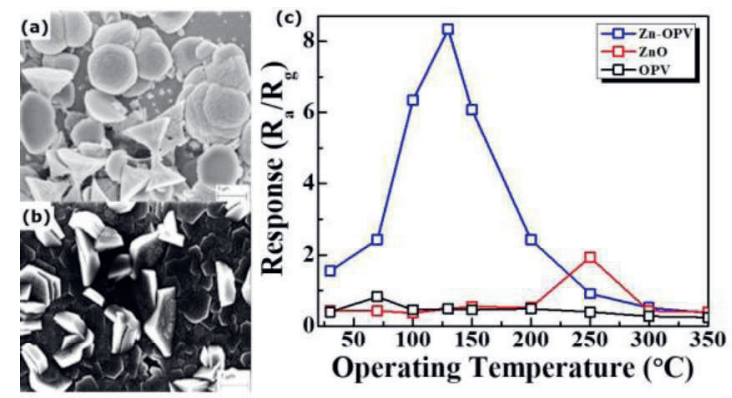

Operating Temperature $\left({ }^{\circ} \mathrm{C}\right)$

Figure 1: FESEM image of (a) ZnO, (b) Zn-OPV, and (c) variation of sensor response with temperature.
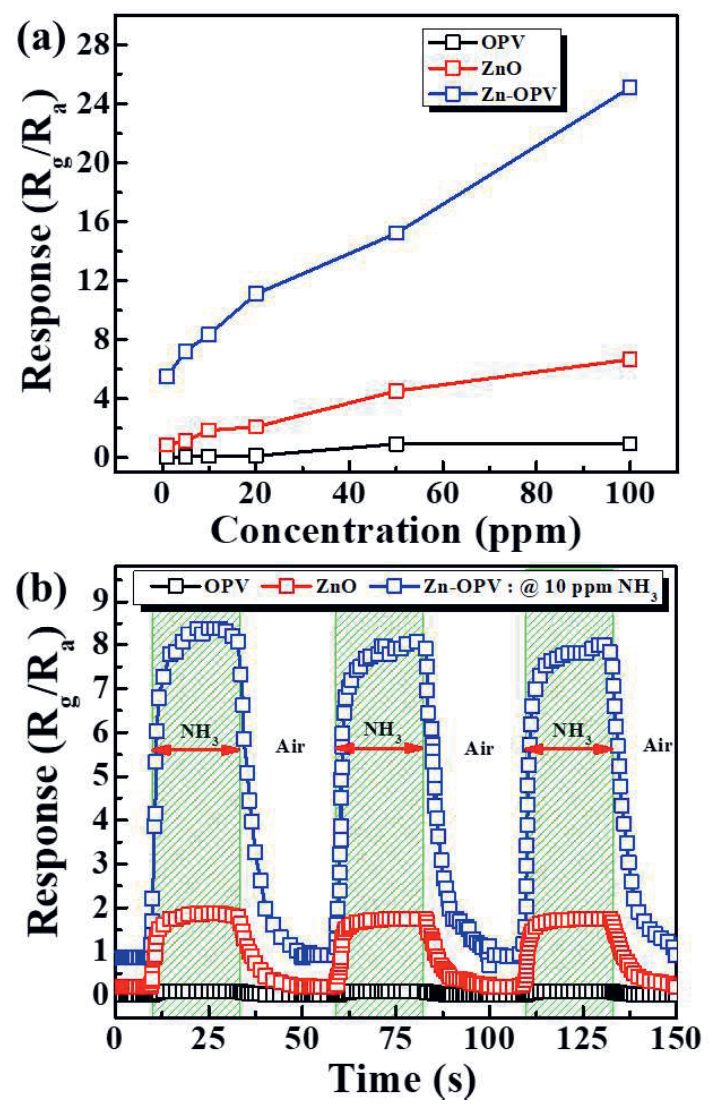

Figure 2: (a) Sensor response towards ammonia gas, and (b) dynamic response at $10 \mathrm{ppm}$ of ammonia.

\section{Conclusion}

In conclusion, we have electrodeposited $\mathrm{Zn}$ OPV nanocomposites films and studied their gas sensing performance. It is seen that the $\mathrm{Zn}$ -
OPV composite exhibited more sensitive performance than its individual constituents towards ammonia gas. The findings show that the response of $\mathrm{Zn}-\mathrm{OPV}$ is approximately 8.5 at $10 \mathrm{ppm}$ of the ammonia. Also, the operating temperature of the composite is lower $\left(120^{\circ} \mathrm{C}\right)$ in comparison to that of $\mathrm{ZnO}$ which is $\sim 250{ }^{\circ} \mathrm{C}$.

\section{Acknowledgement}

Biswajit Mandal and Ritesh Bhardwaj are grateful to Ministry of Electronics and Information Technology (MeitY), Government of India for providing fellowship under Visvesvaraya PhD scheme for Electronics and IT. Prof. Shaibal Mukherjee is thankful to MeitY, Government of India for Young Faculty Research Fellowship (YFRF) under Visvesvaraya PhD scheme for Electronics and IT. Authors are very thankful to SEM and XRD facilities at Sophisticated Instrument Centre (SIC) of IIT Indore.

\section{References}

[1] Bochenkov VE, Sergeev GB. Sensitivity, Selectivity, and Stability of Gas-Sensitive, Metal oxide nanostructures and their applications, $\mathbf{3}$, 31-52 (2010).

[2] Bandgar DK, Navale ST, Nalage SR, Mane RS, Stadler FJ, Aswal DK, et al. Simple and lowtemperature polyaniline-based flexible ammonia sensor: a step towards laboratory synthesis to economical device design, Journal of Material Chemistry C 3, 9461-8 (2015); doi: 10.1039/C5TC01483B.

[3] Sofos M, Goldberger J, Stone DA, Allen JE, Ma $Q$, Herman DJ, et al. A synergistic assembly of nanoscale lamellar photoconductor hybrids, Nature Materials 8, 68-75 (2009); doi: 10.1038/nmat2336.

[4] Besar K, Ardoña HAM, Tovar JD, Katz HE. Demonstration of Hole Transport and Voltage Equilibration in Self-Assembled $\pi$-Conjugated Peptide Nanostructures Using Field-Effect Transistor Architectures, ACS Nano 9, 12401-9 (2015); doi: 10.1021/acsnano.5b05752.

[5] Mouet T, Devers T, Telia A, Messai Z, Harel V, Konstantinov K, et al. Growth and characterization of thin $\mathrm{ZnO}$ films deposited on glass substrates by electrodeposition technique, Applied Surface Science 256, 4114-20 (2010); doi: 10.1016/j.apsusc.2010.01.093.

[6] Praveen VK, Ranjith C, Bandini E, Ajayaghosh A, Armaroli N. Oligo(phenylenevinylene) hybrids and self-assemblies: versatile materials for excitation energy transfer, Chemical Society Reviews 43, 4222 (2014); doi: 10.1039/c3cs60406c. 